\title{
A PROCESS TO SIMULTANEOUSLY PRODUCE A HIGH DIACYLGLYCEROL OIL AND A CAROTENES-ENRICHED TRIACYLGLYCEROL OIL FROM OIL PALM FRESH FRUIT BUNCHES
}

\author{
NABILAH KAMALIAH MUSTAFFA*; HARRISON LIK NANG LAU* and SOH KHEANG LOH*
}

\begin{abstract}
Diacylglycerol (DAG) oil has great potential in overcoming the obesity problem and weight-related disorders. This article attempted to produce high DAG oil directly from the oil palm fresh fruit bunches (FFB). The FFB were cut into smaller portions and subjected to different storage conditions. After a fiveday storage, the oil was extracted and partially refined, and then subjected to two stages of multistage short path distillation at a pressure of $<10 \mathrm{mTorr}$ and a temperature of $>120^{\circ} \mathrm{C}$. At the end of these processes, two different oil fractions were obtained, i.e. the final distillate which contained $60 \mathrm{wt} \%$ of DAG, and the residual oil which was equivalent to the refined palm oil but enriched with carotenes.
\end{abstract}

Keywords: palm oil, lipase hydrolysis, free fatty acid, carotene, short path distillation.

Date received: 18 July 2017; Sent for revision: 19 July 2017; Received in final form: 30 October 2017; Accepted: 5 July 2018.

\section{INTRODUCTION}

Crude palm oil (CPO) is derived from the outer layer, i.e. the mesocarp of the fresh oil palm fruit. The typical compositions of $\mathrm{CPO}$ are $>90 \mathrm{wt} \%$ triacylgycerols (TAG), $5 \mathrm{wt} \%$ to $7 \mathrm{wt} \%$ diacylglycerols (DAG), $3 \mathrm{wt} \%$ monoacylglycerols (MAG) and $2 \mathrm{wt} \%$ to 5 wt $\%$ free fatty acids (FFA). During the CPO refining, the FFA is removed to $<0.05 \mathrm{wt} \%$ while the MAG, DAG and some of its phytonutrients, e.g. palm vitamin $E$ are distilled partially yielding palm fatty acid distillate as a processing residue. Due to an increased incidence of obesity worldwide, research in the late 1990s has been geared towards improving the dietary oil (vegetable oils) with high DAG especially at the 1, 3-position of the triglyceride backbone which has been found less potent in body fat deposits (Brent and Naburo, 2003; Phuah et al., 2015). It was discovered that, a high intake of DAG oil has resulted in a lower level of serum TAG for

Malaysian Palm Oil Board

6 Persiaran Institusi, Bandar Baru Bangi,

43000 Kajang, Selangor, Malaysia.

E-mail: nabilah@mpob.gov.my maintaining a healthy body weight and body fat (Brent and Naburo, 2003).

Normally, fruit starts to develop at a stage of two weeks after anthesis (WAA) and the lipid starts to deposit in the mesocarp at around 15 WAA. Commercially, the synthesis of TAG in the oil palm mesocarp increases rapidly from 16 WAA parallel to the accumulation of the total lipids, reaching their peak at 20 WAA (Sundram et al., 2003). The TAG biosynthesis does not produce MAG and so its presence in tissue extracts is probably a consequence of lipolytic activity. As oil palm fruits ripen naturally, the fresh fruit bunches (FFB) is subjected to enzymatic hydrolysis in the presence of lipase. During the ripening process, the percentages of the 1,3-diacylglycerol (1,3-DAG) increases while that of the 1-2 isomer (1,2- DAG) decreases with progressive accumulation of TAG. Siew and $\mathrm{Ng}$ (1995) discovered that the configurations of DAG in palm oil are dependent on the degree of FFB ripeness and the lipase hydrolytic degradation. More DAG is found in ripe and over-ripe oil palm fruits, and in fruits which are not processed immediately. As such, the 1,3- to 1,2-DAG ratio serves as a useful indicator for the FFB storage conditions and quality. The ripe 
FFB stored over a 10-day ripening period will have the configurations of the DAG isomers changed (Siew and $\mathrm{Ng}, 1995$ ). The 1,3 to 1,2-DAG ratio has increase rapidly during the first few days of the FFB storage from 0.2 to 0.3 due to the hydrolysis by lipase in the fruits. Contrarily, palm oil stored at a higher temperature of $60^{\circ} \mathrm{C}$ and $100^{\circ} \mathrm{C}$ shows significant changes in DAG configurations compared to that of FFB at ambient storage condition over the same period of time. These findings have concluded that the fruit maturity and storage condition affect the DAG contents and compositions of palm oil from FFB, and the storage temperature influences the most on the DAG ratio.

On the other hand, the FFB that is exposed to temperature lower than the ambient has seen a significant increase in the FFA. Ravigadevi and Ahmad (2002) demonstrated that the enzyme in the FFB is highly activated at the lower temperature $\left(15^{\circ} \mathrm{C}\right.$ to $\left.-20^{\circ} \mathrm{C}\right)$. This effect is most pronounced when the fruits are stored at $5^{\circ} \mathrm{C}$ causing the rise in FFA by up to $70 \mathrm{wt} \%$.

Chemical glycerolysis is a common method used in the production of DAG oil via high temperature and catalyst (Satriana et al., 2016). Oil containing TAG reacts with alkali catalyst to achieve the glycerolysis process. The produced DAG oil is further neutralised and stripped using steam to remove the unwanted glycerol residual, and then subjected to molecular distillation to remove the MAG. The resulting oil contains $>80 \mathrm{wt} \%$ of the desired DAG, $<15 \mathrm{wt} \%$ TAG and $<3 \mathrm{wt} \%$ MAG (Jacobs et al., 2006). However, the limiting factor in chemical glycerolysis is most concerning the poor miscibility of the oil and glycerol at low temperatures, hence low mass transfer and overall reaction rate (Satriana et al., 2016).

Other preferred enzymatic approaches to produce DAG oils are lipase-catalysed esterification of fatty acids with glycerol and hydrolysis of vegetable oils. The former partially hydrolyses of TAG followed by the esterification of the oil to reach a high DAG purity $>80 \mathrm{wt} \%$ (Yamada et al., 2001), while the latter is conducted at selectively mild reaction condition leading to oil enriched with certain fatty acids (Murty et al., 2002; Rupani et al., 2012). Therefore, partial hydrolysis of palm olein using commercial enzymes is able to increase its DAG content, making the products containing this high-DAG oil more competitive (Mohsen et al., 2015).

Lately, molecular distillation, also known as short path distillation (SPD), is much sought after, as it offers a gentle temperature separation process and at reduced pressure to significantly reduce the residence time of the distillate and preserve its stability. This distillation technique is generally safe to separate and purify thermally unstable compounds (i.e. those with low vapour pressure and high molecular weights) with minima thermal decomposition (Patricia et al., 2009). Using SPD, it is possible to simultaneously produce two types of palm oil, i.e. a high $(>8 \mathrm{wt} \%)$ and low $(<8 \mathrm{wt} \%$, high in TAG) DAG oil where the palm oil is subjected to at least one stage of SPD under pressure $\leq 0.01$ Torr and temperature $\leq 300^{\circ} \mathrm{C}$ (Choo et al., 2007). In particular, conventional distillation is to be avoided when the intended oil has much of the thermally unstable and low vapour pressure components such as MAG. This article demonstrated a green process to simultaneously produce a high DAG oil from oil palm FFB via SPD without the addition of lipases and other chemicals, and a residual oil enriched with carotene.

\section{MATERIALS AND METHOD}

\section{Materials}

The oil palm FFB were collected from MPOBUKM plantation (Selangor, Malaysia). The FFB used were obtained from oil palms aged 6 to 7 years. All solvents used were purchased from Merck (Darmstadt, Germany) and were of chromatographic or analytical grade.

\section{Storage Conditions}

A few storage conditions were investigated to prolong the hydrolysis process of the harvested FFB. The cut FFB portions (Figure 1) were stored at different controlled conditions, i.e. room temperature $\left(24^{\circ} \mathrm{C}\right.$ to $\left.32^{\circ} \mathrm{C}\right)$, temperature of $15^{\circ} \mathrm{C}$ and, exposed to sunlight, for five days.

\section{Analyses}

The FFA of the extracted oil from the stored FFB was determined via MPOB Test Method p2.5: 2004 (MPOB, 2005), by titrating the oil with $\mathrm{NaOH}$ solution using phenolphthalein as the indicator to the first permanent pink colour. The Equation (1) was used to calculate the percentage of FFA.

$$
\text { FFA }(\%)=\mathrm{V} \times \mathrm{N} \times 25.6 / \mathrm{W} \quad \text { Equation (1) }
$$

where $V$ is the volume in $\mathrm{ml}$ of titration solution $(\mathrm{NaOH})$ used, $N$ is the normality of the titration solution $(\mathrm{NaOH})$, and $W$ is the weight of the sample of oil in grams.

The DAG and TAG contents of the extracted oil were determined using a gas chromatography - flame ionisation detector (GC-FID) as described by Lau et al. (2005), by using a rapid technique for the quantitative determination of a mixture of FFA, acylglycerols, sterols and squalene in a single GC-FID injection of vegetable oils, with special reference to palm oil. The carotene content of the residual 

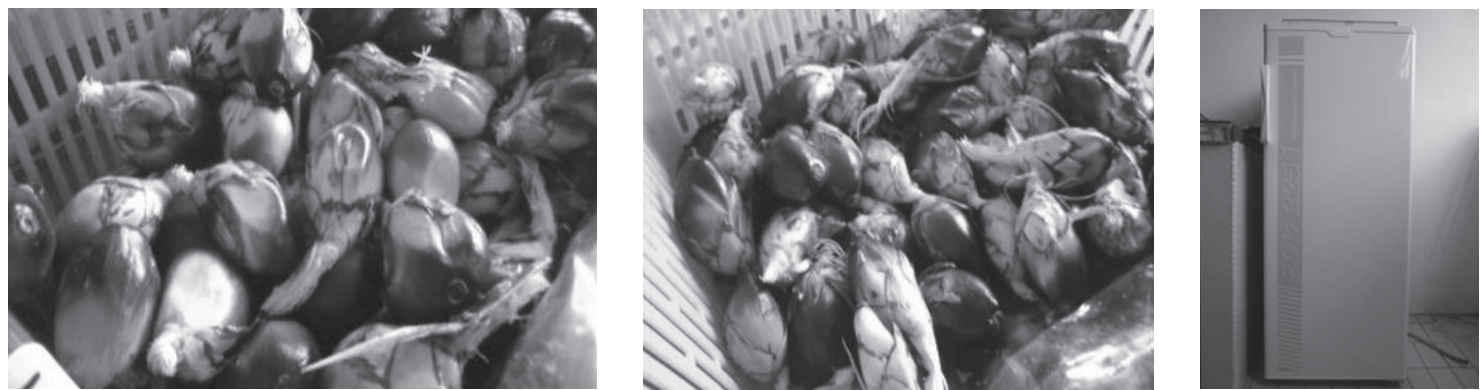

Figure 1. Fresh fruit bunches (FFB) portions storage conditions: (a) room temperature, (b) exposed to sunlight and (c) at $15^{\circ} \mathrm{C}$.

oil was determined via MPOB Test Method p2.6: 2004 (MPOB, 2005), using a UV spectrophotometer (model UV-1800, Shimadzu). Prior to analysis, sample were melted at $60^{\circ} \mathrm{C}-70^{\circ} \mathrm{C}$ and homogenised thoroughly. About $10 \mathrm{mg}$ of the sample (residual oil) were diluted with $25 \mathrm{ml}$ of hexane in volumetric flask. The solution was then transferred to a $10 \mathrm{~mm}$ cuvette and the absorbance was read at $446 \mathrm{~nm}$. The Equation (2) was used to calculate the concentration of carotene in the oil expressed as ppm.

$$
\text { Carotene }=(\mathrm{V} \times 383 \times \mathrm{a}) / 100 \mathrm{~W} \quad \text { Equation }(2)
$$

where $V$ is the volume used for analysis, $a$ is absorbance of sample at $446 \mathrm{~nm}, 383$ is the extinction coefficient for carotenoids, and $W$ is weight of sample in grams.

\section{Oil Extraction, Refining and Distillation}

At the end of each five-day storage period, the chopped FFB was peeled using a knife to separate the mesocarp which was immediately dried in an oven at $60^{\circ} \mathrm{C}$. The dried mesocarp was extracted with n-hexane using a conventional soxhlet extractor (Figure $2 a$ ) for $8 \mathrm{hr}$ at $70^{\circ} \mathrm{C}$. At this stage, the extracted oil contained high DAG and FFA.
The hexane in the extracted oil was recovered via a rotary vacuum evaporator. The extracted oil was pumped dry under vacuum to remove the remaining water and the oil weight was recorded. The oil was then partially refined to yield the degummed and bleached oil prior to distillation without the deodourisation step in order to retain the carotene. The oil was first heated up to a temperature of about $90^{\circ} \mathrm{C}$ before it is treated with phosphoric acid. The dosage of phosphoric acid used is within the range of $0.05 \%-0.1 \%$ of oil weight. The degummed oil was then treated with bleaching earth and oil was heated up to a temperature of about $100^{\circ} \mathrm{C}$. The dosage of acid activated clay used is within the range of $0.5 \%-2.0 \%$ by weight of oil and the contact time with continuous agitation is about $30 \mathrm{~min}$. The degummed and bleached oil was then subjected to first stage multistage SPD (Figure $2 b$ ) at $\geq 130^{\circ} \mathrm{C}$ under vacuum $(\leq 10$ mTorr) to remove the FFA. The oil was distilled until a low FFA content in the residual oil was reached. Then, the residual oil from the first multistage SPD was once again subjected to the second multistage SPD at $\geq 170^{\circ} \mathrm{C}$ under vacuum ( $\leq 10$ mTorr). Samples for both the distillation processes, i.e. the distillates and the residual oil at each stage were analysed for FFA, MAG, DAG, TAG and carotene contents. (a)

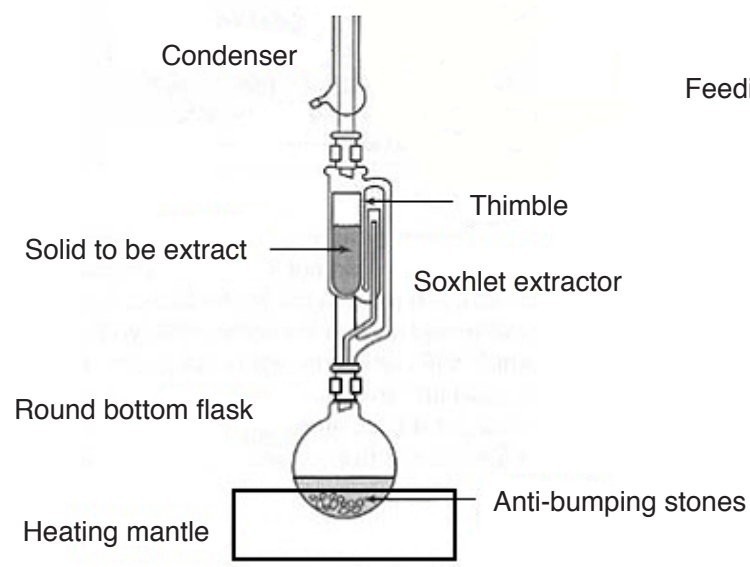

(b)

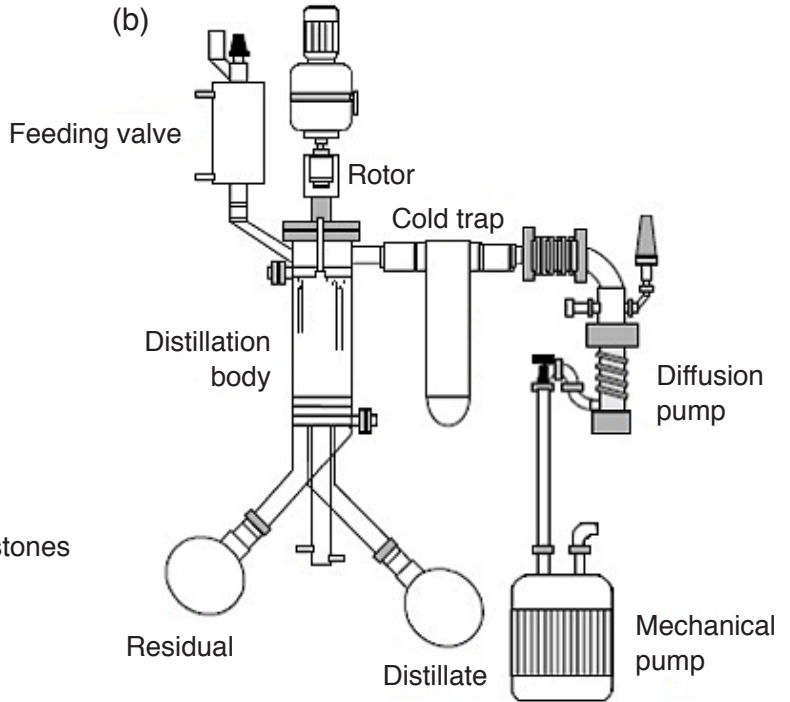

Figure 2. Apparatus set up for (a) solvent extraction and (b) short path distillation system. 


\section{RESULTS AND DISCUSSION}

The storage of the ripe oil palm FFB had resulted in compositional changes of the FFA (Figure 3) and the glycerides components (Figure 4). According to Siew and $\mathrm{Ng}$ (1997), the composition of DAG in palm oil is dependent on the degree of FFB ripeness and the extent of hydrolytic degradation. In Figure 3, the FFB portions stored at $15^{\circ} \mathrm{C}$ showed the highest FFA rise in five days compared to other storage conditions. This proved that the enzyme (lipase) in FFB was activated at the lower temperature. The increase of FFA in the fruits was caused by the action of the endogenous oil palm lipases. Any increase in FFA after Day 5, was probably caused by microbial fungus, as visually evidenced by the presence of fungus on the fruits.

The activity of lipase enzyme remains high after the FFB has been harvested from the field which then can be controlled to yield an optimum content of DAG in the palm oil. Siew (2000) found that the DAG content could increase during the storage of palm oil under different conditions. The DAG content of the oil extracted from FFB portions had increased from the initial five $\mathrm{wt} \%$ to at least $13 \mathrm{wt} \%$ (Figure 4) after five days of storage under

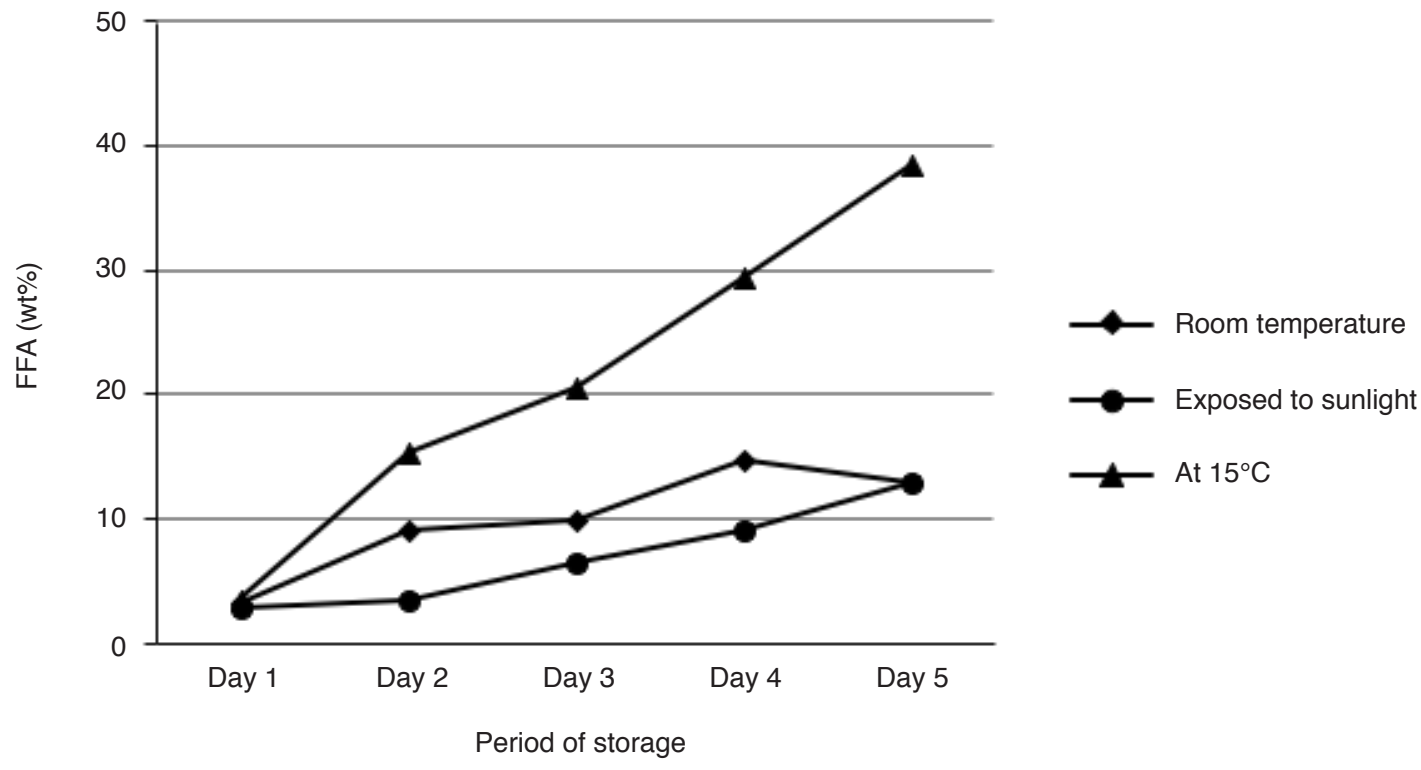

Figure 3. Percentage of free fatty acid (FFA) in the extracted oil.

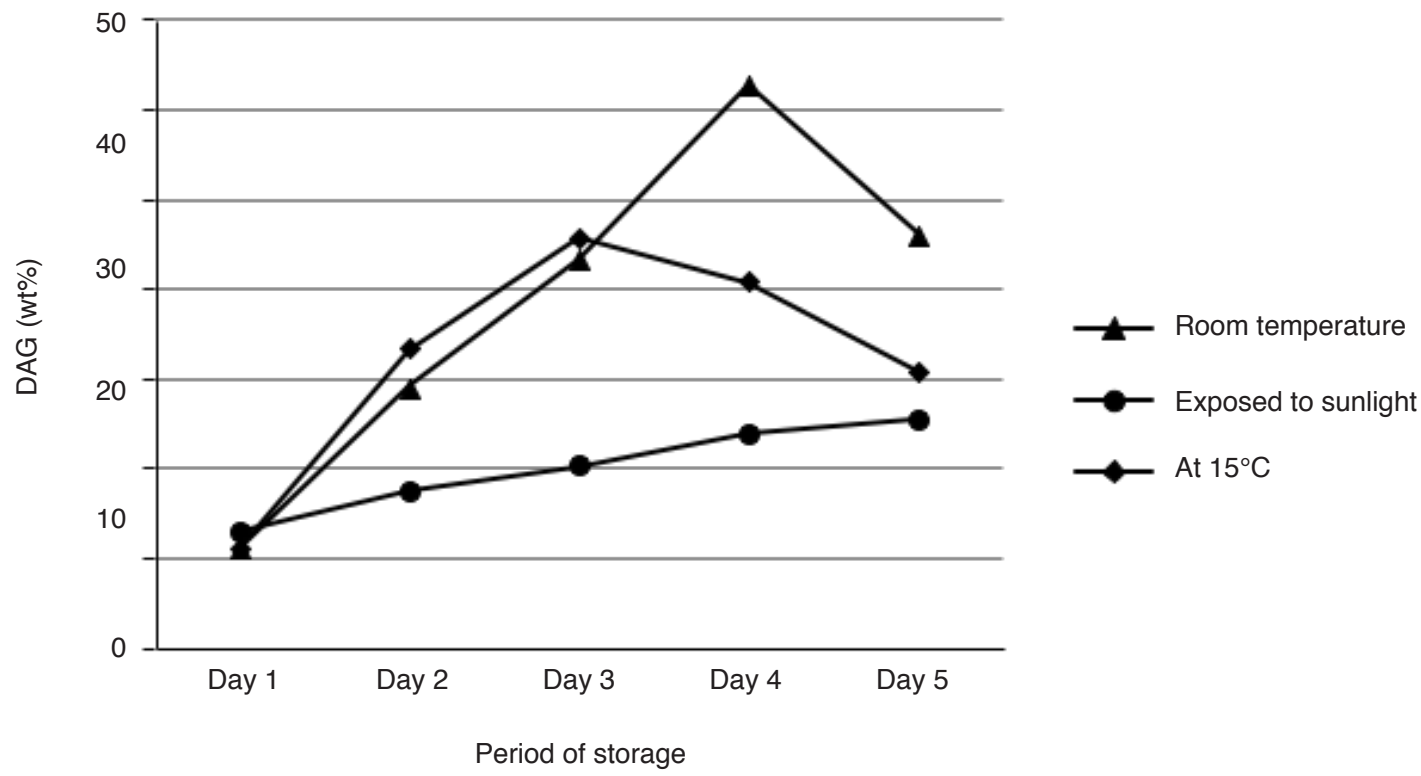

Figure 4. Percentage of diacylglycerol (DAG) in the extracted oil. 
different conditions. The total DAG content at room temperature increased from $5 \mathrm{wt} \%$ to $31 \mathrm{wt} \%$ after four days of storage while that at $15^{\circ} \mathrm{C}$ from $5 \mathrm{wt} \%$ to $23 \mathrm{wt} \%$ after three days of storage. Interestingly, some amount of TAG in the oil had been hydrolysed into DAG with parallel increment of FFA.

The differences in the DAG content in CPO and the extracted oil in this study (high in DAG) were shown in Figure 5. The increased FFA in high DAG oil was due to the rapid hydrolysis of lipase in the FFB. In normal practice in palm oil mills, FFB are cooked immediately after harvesting to avoid generating unacceptable levels of FFA. In this study, the FFB were not subjected to heat in order to prolong the lipase hydrolysis so as to yield higher partial glycerides, i.e. DAG but unfortunately accompanied by increased formation of FFA.

The high DAG and FFA oil extracted from the FFB (stored at $15^{\circ} \mathrm{C}$ ) was subjected to two stages of multistage SPD to remove the unwanted FFA formed. The feed for the second stage multistage SPD was obtained from the residual of the first multistage SPD. The results (Table 1) showed that the first distillate from the first stage of multistage SPD at $130^{\circ} \mathrm{C}$ contained $55 \mathrm{wt} \%$ of FFA while that of the residual oil only $0.5 \mathrm{wt} \%$. In order to

(a)

Current Chromatogram (s)

(b)

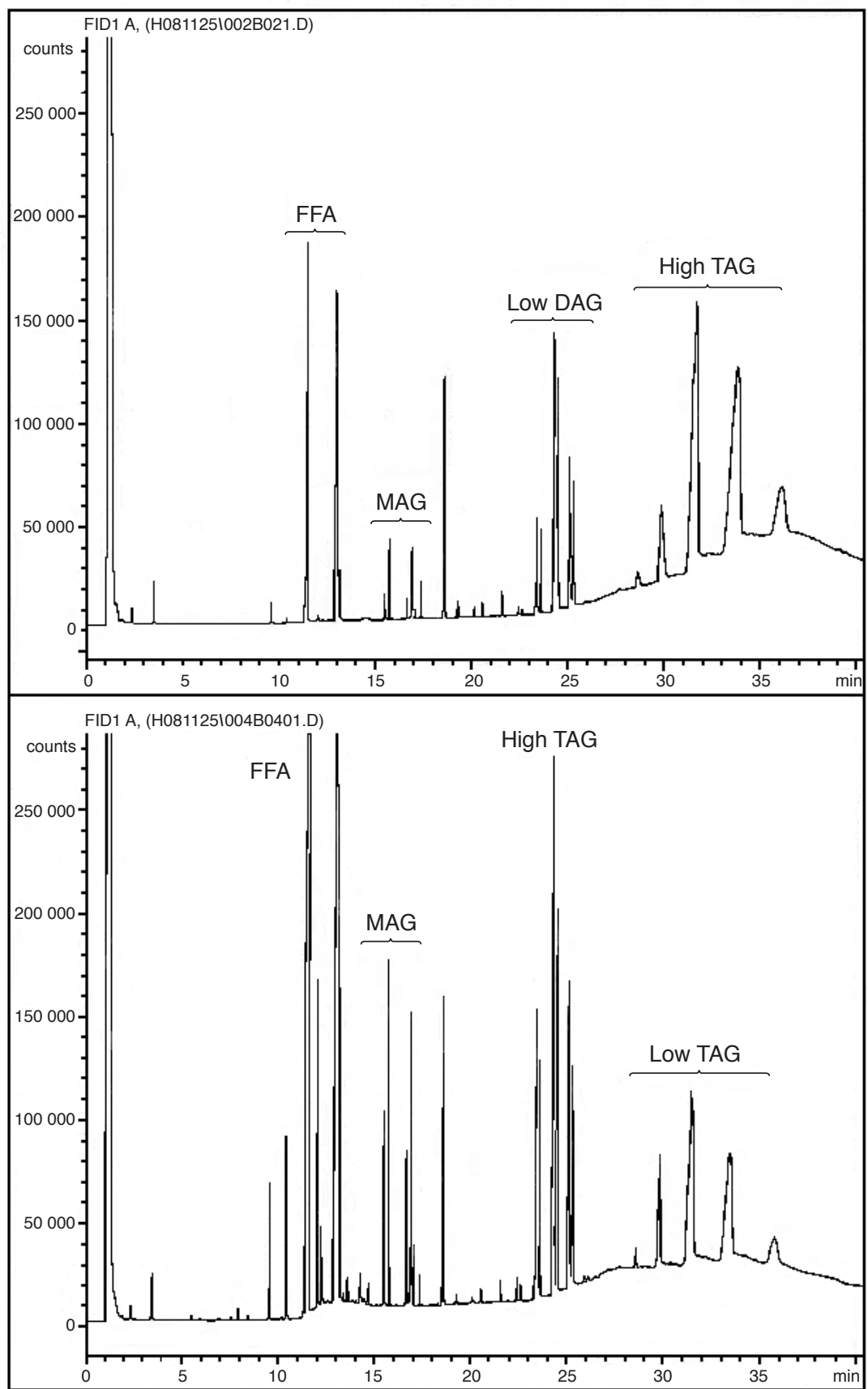

Figure 5. The differences in fatty acid compositions, i.e. free fatty acid (FFA), monoacylglycerol (MAG), diacylglycerol (DAG) and triacylglycerol (TAG) of (a)normal palm oil and (b) palm oil after prolonged storage. 
obtain high DAG oil, the residual oil from the first multistage SPD (with $25 \mathrm{wt} \%$ DAG) was subjected to the second multistage SPD at temperature $170^{\circ} \mathrm{C}$. The resulting second stage distillate (final distillate) contained $66 \mathrm{wt} \%$ of $\mathrm{DAG}$ and $\approx 1$ wt $\%$ FFA (Table 2). The residual oil at this stage was closer to the normal refined palm oil enriched with carotene, i.e. 550 ppm as it was just partially refined without the deodorisation step. However, the TAG content in the residual oil is lower than the normal refined palm oil (Table 2) as some amount of the TAG had been distilled out due to the high temperature applied. Figures 6 and 7 show the GC chromatograms of the feed and the final distillate from the second multistage SPD, respectively with significant reduced FFA and increased DAG.

\section{CONCLUSION}

The lipase in the oil palm FFB had been better activated at below the ambient temperature preferably at $15^{\circ} \mathrm{C}$. Palm oil with high DAG content can be obtained after five days of FFB storage at room temperature but with parallel increment of the unwanted FFA. The SPD of the extracted oil from

TABLE 1. COMPOSITIONS OF OIL IN THE FIRST MULTISTAGE VACUUM DISTILLATION

\begin{tabular}{|c|c|c|c|c|}
\hline Sample & FFA $(w t \%)$ & MAG $(\mathbf{w t} \%)$ & DAG (wt $\%)$ & TAG $(\mathbf{w t} \%)$ \\
\hline Extracted oil & \multicolumn{4}{|c|}{ First stage short path distillation } \\
\hline Distillate (1) & 55.2 & 2.2 & 14.0 & 28.5 \\
\hline Residual oil (1) & 6.9 & 1.2 & 20.0 & 71.9 \\
\hline Residual oil (2) & 0.5 & 1.7 & 25.1 & 72.7 \\
\hline
\end{tabular}

Note: FFA - free fatty acid. MAG - monoacylglycerol. DAG - diacylglycerol. TAG - triacylglycerol.

TABLE 2. COMPOSITIONS OF OIL AFTER SECOND MULTISTAGE VACUUM DISTILLATION

\begin{tabular}{|c|c|c|c|c|}
\hline Sample & FFA $(w t \%)$ & MAG (wt $\%)$ & DAG $(w t \%)$ & TAG $(\mathbf{w t} \%)$ \\
\hline Residual oil (2) from Table 1 & \multicolumn{4}{|c|}{ First stage short path distillation } \\
\hline Distillate (1) & 0.7 & 1.8 & 46.3 & 51.2 \\
\hline \multirow[t]{2}{*}{ Residual oil (1) } & 0.4 & 1.7 & 18.8 & 79.1 \\
\hline & \multicolumn{4}{|c|}{ Second stage short path distillation [feed=distillate (1)] } \\
\hline Residual oil (2) & 0.6 & 0.9 & 34.7 & 63.8 \\
\hline Refined palm oil ${ }^{\mathrm{a}}$ & $<0.1$ & 0.1 & 6.9 & 93.0 \\
\hline
\end{tabular}

Note: FFA - free fatty acid. MAG - monoaclyglycerol. DAG - diacylglycerol. TAG - triacylglycerol. Source: ${ }^{a} \mathrm{Gee}$ (2007).

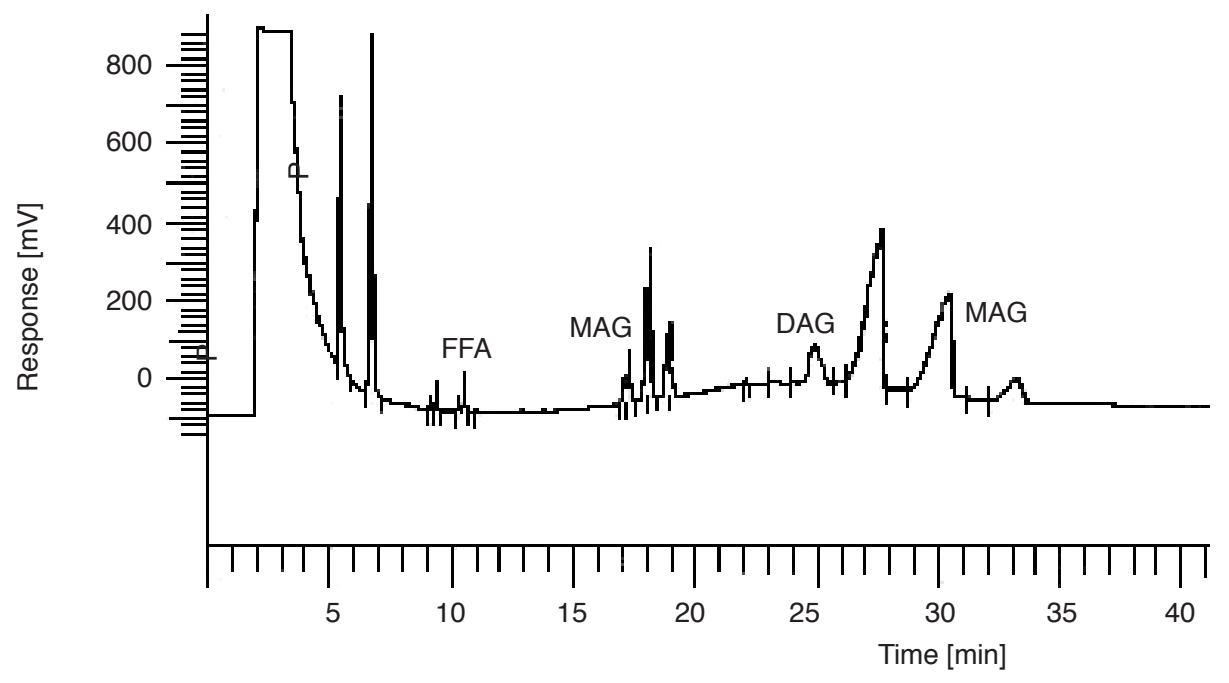

Figure 6. Chromatogram of feed material before subjected to multistage vacuum distillation. 


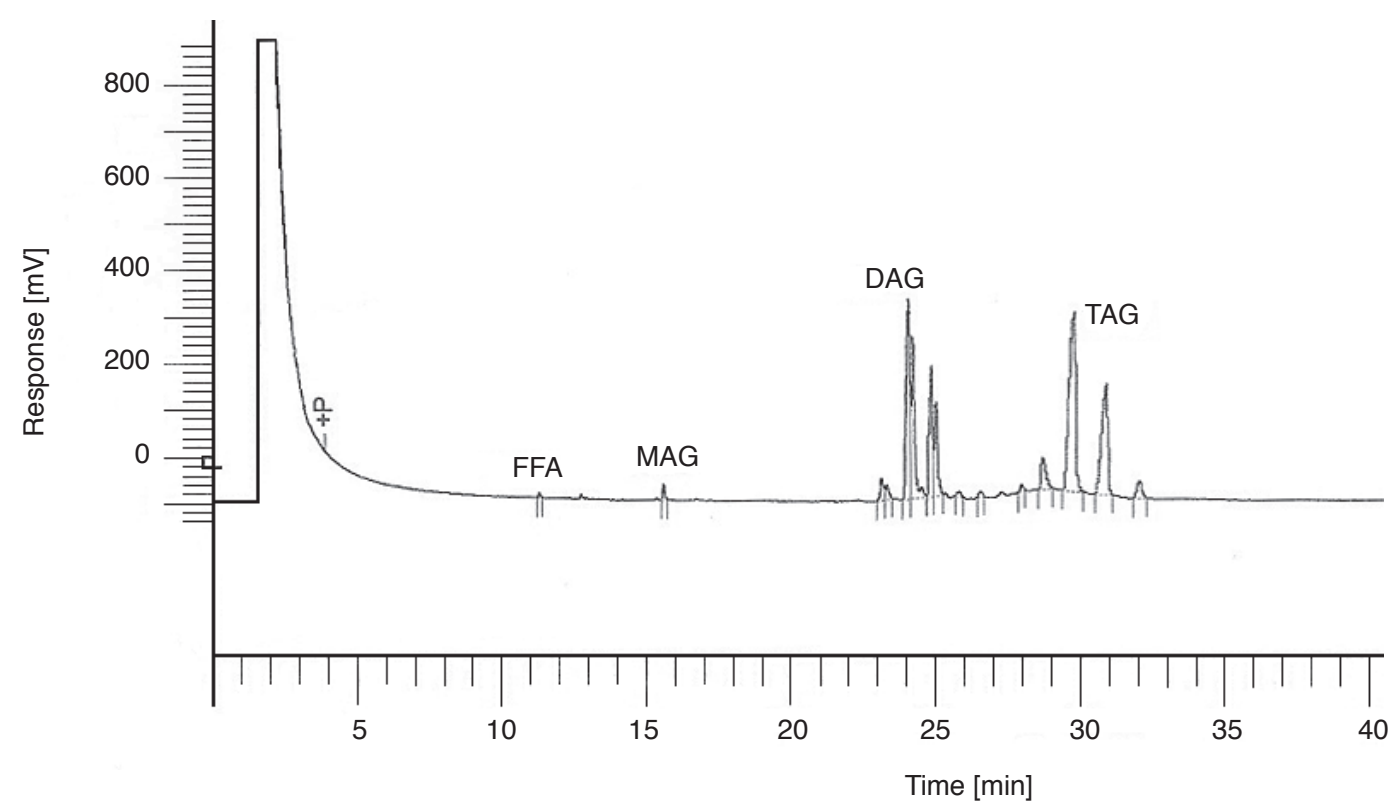

Figure 7. Chromatogram of final distillate from the second multistage vacuum distillation.

the stored FFB was able to produce a final distillate high in DAG and a residual oil closer to the normal refined palm oil at the second multistage SPD. However, much needs to be done to upgrade the oil to a commercial DAG oil.

\section{ACKNOWLEDGEMENT}

The authors thank the Director-General of MPOB for permission to publish this article.

\section{REFERENCES}

BRENT, D F and NABURO, M (2003). Nutritional characteristics of DAG oil. Lipids Vol. 38: 129-132.

CHOO, Y M; PUAH, C W; MA, A N and YUSOF, B (2007). Production of edible oil. Patent No. US $2007 / 0021625$ A1.

GEE, P T (2007). Analytical characteristic of crude and refined palm oil fractions. Eur. J. Lipid Sci. Technol., 109: 373-379.

JACOBS, L; IMMOK, L and GEORGE, P (2006). Chemical process for the production of 1,3-diglycerides oil. Patent No. US 7081542 B2.

LAU, H L N; PUAH, C W; CHOO, Y M; MA, A N and CHUAH, C H (2005). Simultaneous quantification of free fatty acids, free sterols, squalene, and acylglycerol molecular species in palm oil by hightemperature gas chromatography-flame ionization detection. Lipids Vol. 40: 523-528.
MOHSEN, M; JAMSHID, F and REZA, E K (2015). Efficacy of some commercial lipases in hydrolysis of palm olein for the production of free fatty acids and diacylglycerol oil. J. Oil Palm Res. Vol. 27: 250-260.

MPOB (2005). A Compendium of Test on Palm Oil Products, Palm Kernel Products, Fatty Acids, Food Related Products and Others. MPOB, Bangi.

MURTY, V R; BHAT, J and MUNISWARAN, P K A (2002). Hydrolysis of oils by using immobilized lipase enzyme: A review. Biotechnology and Bioprocess Engineering, 7: 57-66.

PATRICIA, B L F; GLAUCIA, M F P; MARIA, R $W$ and RUBENS, M F (2009). Monoglyceride and diglyceride production through lipase-catalyzed glycerolysis and molecular distillation. Appl. Biochem. Bioethanol., 160(7): 1879-1887.

PHUAH, E T; TANG, T K; LEE, Y Y; THOMAS, S Y C; TAN, C P and LAI, O M (2015). Review on the current state of diacylglycerol production using enzymatic approach. Food Bioprocess. Technol., 8: 1169-1186.

RAVIGADEVI, S and AHMAD, K (2002). Selection for lipase activity in the oil palm. MPOB Information Series No. 158. http://palmoilis.mpob.gov.my/ publications/TOT/tot2002/tt141.pdf

RUPANI, B; KODAM, K; GADRE, $\mathrm{R}$ and NAJAFPOUR, G D (2012). Lipase-mediated hydrolysis of flax seed oil for selective enrichment of $\alpha$-linolenic acid. Eur. J. Lipid Sci. Technol., 114 (11): 1246-1253. 
SATRIANA, N A; YANTI, M L; ADISALAMUN; MUHAMMAD, D S and WAN, A W M (2016). Diacylglycerol-enriched oil production using chemical glycerolysis. Eur. J. Lipid Sci. Technol., 118.

SIEW, W L (2000). Enhancement of oil quality. Advances in Oil Palm Research (Yusof Basiron; Jalani, B S and Chan, K W eds.). Vol. 2. MPOB, Bangi. p. 935-937.

SIEW, W L and NG, W L (1997). Refining technology and quality. Proc. of the National Seminar on Palm Oil
Milling, Refining Technology and Quality. PORIM, Bangi. p. 124-140.

SIEW, W L and NG, W L (1995). Diglyceride content and composition as indicators of palm oil quality. $J$. Sci. Food Agri., 69: 73-76.

SUNDRAM, K; SAMBANTHAMURTHI, R and TAN, Y A (2003). Palm fruit chemistry and nutrition. Asia Pacific J. Clin. Nutr., 12: 355-362.

YAMADA, Y; SHIMIZU, M; SUGIURA, $M$ and YAMADA, $N$ (2001). Process for producing diglycerides. Patent No. US 6,261,812B1.

\section{Early View}

Beginning October 2017, Early View is available in JOPR Microsite.

Articles which have been accepted for publication, edited and checked by authors are published online as Early View in Articles in Press section in the JOPR Microsite before the final online and print version of JOPR is published. Early View (also known as online first by other journals) articles although do not yet have page No. and volume/issue details but has been assigned to a Digital Object Identifier (DOI) No. for tracking and citations purposes. This is to accelerate the publication and dissemination of the latest research output.

To view all the articles currently available in Early View, visit http:/ / jopr.mpob.gov.my/ ?mycat=InPress 